\title{
Interactions between sea surface temperature over the South Atlantic Ocean and the South Atlantic Convergence Zone
}

\author{
Rosane Rodrigues Chaves ${ }^{1}$ and Paulo Nobre \\ Centro de Previsão de Tempo e Estudos Climáticos-CPTEC, Instituto Nacional de Pesquisas Espaciais - INPE, Brazil \\ Received 16 September 2003; revised 5 November 2003; accepted 3 December 2003; published 11 February 2004.
}

[1] Interactions between the sea surface temperature (SST) over the South Atlantic Ocean $\left(40^{\circ} \mathrm{S}\right.$-Equador) and the South Atlantic Convergence Zone (SACZ) were studied through numerical experiments with an atmospheric general circulation model (AGCM) and an ocean general circulation model (OGCM). The AGCM experiments showed that warm SST anomalies over the South Atlantic tend to intensify the SACZ and shift it northward, while cool SST anomalies over the South Atlantic tend to weaken the SACZ. The OGCM experiments, on the other hand, showed that the intensification of the SACZ contributes to cool the underlying ocean through the reduction of incident shortwave solar radiation, causing the appearance of cold SST anomalies or the weakening of pre-existing warm SST anomalies. The most important finding in this work was the predominance of the cloud/shortwave - SST negative thermodynamic feedback between the atmosphere and the ocean over the southwest tropical Atlantic, this is one order of magnitude larger than the dynamic feedback associated with Ekman pumping. The latter was verified only during strong SACZ events. The results suggest that negative SST anomalies often observed underlying the SACZ represent an ocean response to atmospheric forcing. INDEX TERMS: 3309 Meteorology and Atmospheric Dynamics: Climatology (1620); 3399 Meteorology and Atmospheric Dynamics: General or miscellaneous; 4215 Oceanography: General: Climate and interannual variability (3309); 4223 Oceanography: General: Descriptive and regional oceanography; 4255 Oceanography: General: Numerical modeling. Citation: Chaves, R. R., and P. Nobre (2004), Interactions between sea surface temperature over the South Atlantic Ocean and the South Atlantic Convergence Zone, Geophys. Res. Lett., 31, L03204, doi:10.1029/2003GL018647.

\section{Introduction}

[2] The South Atlantic Convergence Zone (SACZ) has been the focus of recent studies aimed at understanding its variability and to assessing its predictability, thereby improving climate predictions over South America (SA). The search for relationships between SACZ intensity, position, and underlying sea surface temperature anomalies (SSTA) has been the focal point of such studies [e.g., Lenters and Cook, 1999; Robertson and Mechoso, 2000; Barreiro et al., 2002]. The pioneering work of Kalnay et al. [1986] suggests that an atmospheric stationary wave

\footnotetext{
${ }^{1}$ Now at Instituto de Astronomia, Geofísica e Ciências Atmosféricas Universidade de São Paulo, Brazil.
}

Copyright 2004 by the American Geophysical Union. 0094-8276/04/2003GL018647\$05.00 associated with the SACZ was the cause of the cold SSTA observed over the South Atlantic during January 1979. Robertson and Mechoso [2000] showed observational evidence that warm (cold) SSTA are associated with a weaker (stronger) SACZ. According to Doyle and Barros [2002] a positive feedback between positive (negative) SSTA and weak (intense) SACZ activity might enhance the low-level circulation pattern associated with the SACZ seesaw. Barreiro et al. [2002] used an atmospheric general circulation model (AGCM) to study the impact of SSTA on the SACZ and conjectured that convective activity over the land portion of the SACZ is independent of changes in SST.

[3] The present study used the CPTEC/COLA AGCM and NOAA's Geophysical Fluid Dynamics Laboratory (GFDL) Modular Ocean Model (MOM2) oceanic general circulation model (OGCM) to perform sensitivity analysis with prescribed boundary conditions. This allows for consideration of atmosphere and ocean dynamics. The goal of this work is the clarification of cause and effect relationships in the on-going debate about SACZ variability. The structure of this article is as follows: Section 2 presents the methodology, Section 3 shows the results and discussion of the numerical modeling experiments; the conclusions are presented in Section 4.

\section{Methodology}

[4] The CPTEC/COLA AGCM used in the atmospheric experiments has spectral triangular truncation at wave number 62 and 28 sigma levels in the vertical. It uses Kuo parameterization scheme for deep cumulus convection, as in Schneider and Zhu [1998]. Cavalcanti et al. [2002] showed that the CPTEC/COLA AGCM is able of simulate the main features of the global climate. Their results are consistent with analyses of others AGCMs. They showed that the energy budget analysis of radiative fluxes are close to observations, but the unbalance of fluxes in the atmosphere and at the surface indicated that the radiative and cloud scheme parameterizations of the AGCM need to be improved.

[5] Three AGCM experiments were done for the period November 2000 to February 2001. During this period, the equatorial Pacific and large portions of the tropical oceans presented near climatological SST, while positive SST anomalies of the order of $1^{\circ} \mathrm{C}$ were observed over the South Atlantic (Figure 1). A control run was carried out by using observed global SST from NCEP as surface ocean boundary condition. This experiment was referred as ACTR. The others two experiments used a negative and a positive increment added over the South Atlantic (from $40^{\circ} \mathrm{S}$ to 


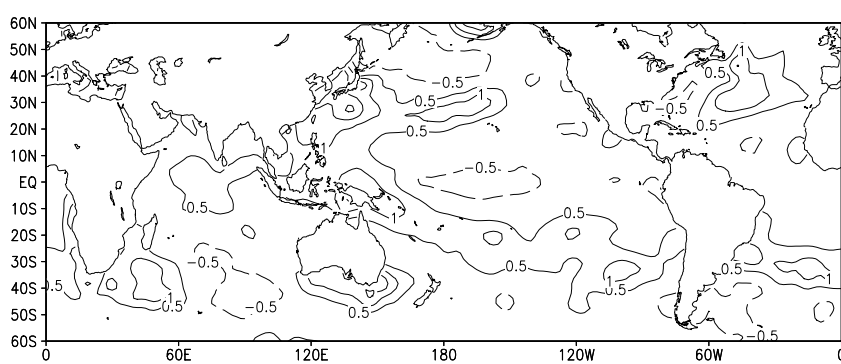

Figure 1. Mean sea surface temperature anomaly field for the period November 2000 to February 2001. Contour interval is $1.0^{\circ} \mathrm{C}$.

Equator and $50^{\circ} \mathrm{W}$ to $20^{\circ} \mathrm{E}$ ), and observed global SST over the remaining oceans. These experiments were referred as $A C$ and $A W$, respectively. The SST fields over the South Atlantic Ocean for the cold and warm experiments were computed using the expressions (1) and (2) below:

$$
\begin{gathered}
S S T_{A C}=S S T_{A C T R}-\left[1+\operatorname{abs}\left(S S T A_{A C T R}\right)\right] \\
S S T_{A W}=S S T_{A C T R}+\left[1+\operatorname{abs}\left(S S T A_{A C T R}\right)\right]
\end{gathered}
$$

where the subscripts $A C T R, A C$, and $A W$ refer to control (i.e., observed SST), cold, and warm experiments, respectively; and SSTA is the observed SST anomaly field to each month considered. The arbitrary SST increments were imposed in the area above considering that the leading EOF of SSTA in the South Atlantic Ocean displayed uniform polarity over most of this basin [Venegas et al., 1997], despite the existence of the South Atlantic monopole to be questionable. According to Palastanga et al. [2002] and Sterl and Hazeleger [2003], the monopole pattern over the South Atlantic seems to be influenced by the inhomogeneous distribution of in-situ observations over the basin, which may lead to erroneous spatial pattern of SSTA variability.

[6] The AGCM was integrated for 120 days, with 5 distinct initial conditions from NCEP operational analysis for 12:00 UTC on 1 November 1995, 1996, 1998, 1999 and 2000 for all experiments ( $A C T R, A C$, and $A W$ ). The December 2000 to February 2001 (DJF) ensemble averages for each experiment were analyzed. A summary of the boundary conditions used for the AGCM experiments is shown in Table 1.

[7] The GFDL MOM2 [Pacanowski et al., 1993] model used in the oceanic experiments was configured over the area $40^{\circ} \mathrm{S}$ to $40^{\circ} \mathrm{N}$ with a sponge layer applied along the northern and southern boundary. The zonal resolution of the OGCM is $1.5^{\circ}$ and the meridional resolution is $0.5^{\circ}$ in the deep tropics $\left(10^{\circ} \mathrm{S}-10^{\circ} \mathrm{N}\right)$, increasing linearly to $3.5^{\circ}$ at

Table 1. Characteristics of the AGCM Experiments: Oceanic Boundary Conditions

\begin{tabular}{ccc}
\hline Experiments & SST South Atlantic & SST over remaining oceans \\
\hline$C T R$ & Nov/2000 to Feb/2001 & Nov/2000 to Feb/2001 \\
$A C$ & negative anomaly & Nov/2000 to Feb/2001 \\
$A W$ & positive anomaly & Nov/2000 to Feb/2001 \\
\hline
\end{tabular}

Table 2. Characteristics of the OGCM Experiments: Atmospheric Boundary Conditions

\begin{tabular}{ccc}
\hline Experiments & Momentum fluxes & SW fluxes \\
\hline OCTR & $A C T R$ & $A C T R$ \\
$O C$ & $A C$ & $A C$ \\
$O W$ & $A W$ & $A W$ \\
OCTR1 & $A C T R$ & Smithsonian climatology \\
OC1 & $A C$ & Smithsonian climatology \\
OW1 & $A W 1$ & Smithsonian climatology \\
\hline
\end{tabular}

$40^{\circ} \mathrm{S}$ and $40^{\circ} \mathrm{N}$. The OGCM was spun up for 31 years using surface climatological momentum fluxes from CPTEC/ COLA AGCM [Cavalcanti et al., 2002] and heat fluxes parameterized using bulk formulas according to Rosati and Miyakoda [1988]. The short-wave (SW) flux was prescribed from Smithsonian Meteorological Table.

[8] The performance of the spin up integration was evaluated by comparison with COADS data. The model reproduces large scale features of the SST fields over the Pacific and Atlantic oceans (figures not shown), such as the east-west SST gradient over the equatorial Pacific, with the cold (warm) water in the east (west) side of the basin, and the warm SST tongue with NW/SE orientation over the South Atlantic in the summer months. Over the southeastern tropical Pacific the SST was significantly reduced, as in the experiments of Huang and Schneider [1995].

[9] Surface wind stress and SW fluxes of the $A C R T, A C$, and $A W$ AGCM experiments were used to integrate the OGCM from November/2000 to March/2001. The others components of the surface heat fluxes were parameterized as in the spin up run. These OGCM experiments were denominated $O C T R, O C$, and $O W$, respectively. To evaluate relative importance of thermodynamic and dynamic feedback processes, the OGCM was forced with momentum fluxes from the AGCM experiments and SW flux prescribed from the Smithsonian Meteorological Tables. These OGCM experiments were denominated OCTR1, OC1 and OW1,
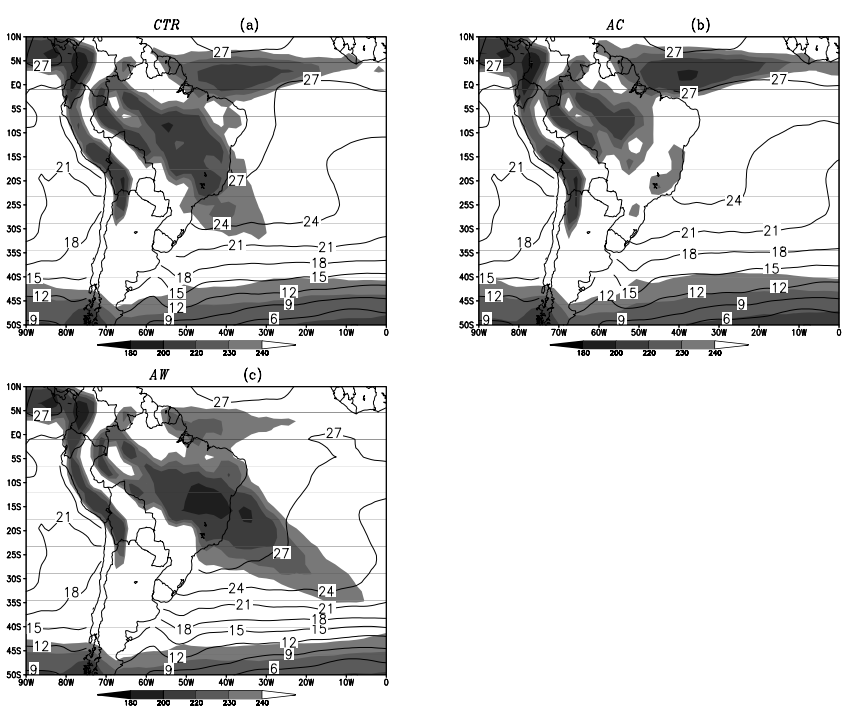

Figure 2. Outgoing Longwave Radiation (shaded; W/m²) and SST (contour; ${ }^{\circ} \mathrm{C}$ ) for (a) $C T R$, (b) $A C$, and (c) $A W$ AGCM experiments. 


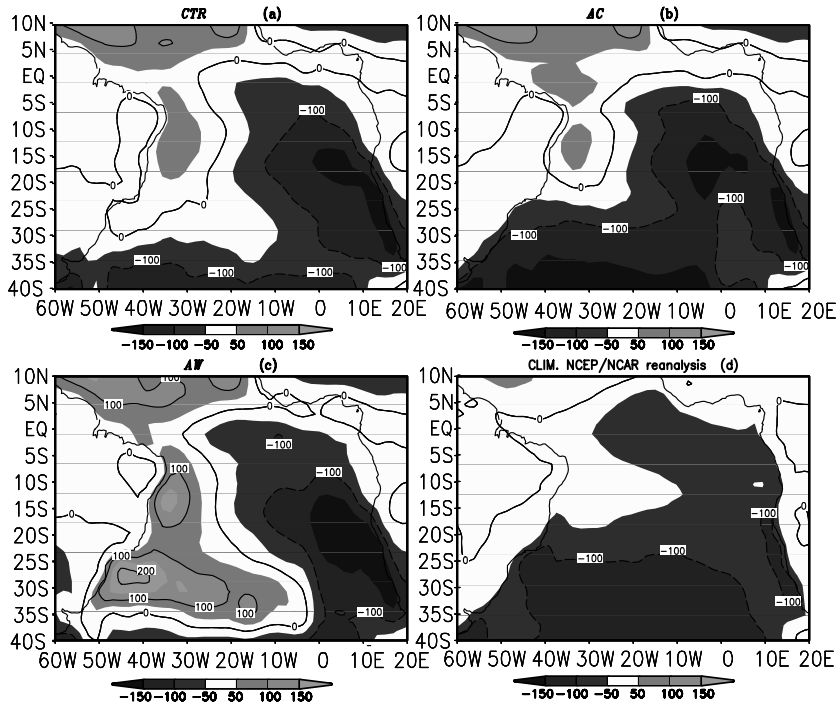

Figure 3. Heat budget $\left(\mathrm{W} / \mathrm{m}^{2}\right)$ for (a) $C T R$, (b) $A C$, (c) $A W$ AGCM experiments, and (d) climatological mean for the December to February from NCEP/NCAR reanalysis.

respectively. A summary of the boundary conditions used for the OGCM experiments is shown in Table 1. Only the SW flux was altered in the experiments because it is the largest component of the energy budget in the region of the South Atlantic during summer, except near the Equator, where the LH flux dominates the exchange of heat between the atmosphere and ocean [Hastenrath, 1995].

\section{Results}

\subsection{AGCM Experiments}

[10] Figure 2 shows the outgoing longwave radiation (OLR) patterns and SST of the CTR, $A C$ and $A W$ AGCM experiments. In the cold experiment (Figure 2b) a significant change of the convection pattern over South America was noticeable, with the absence of the subtropical portion
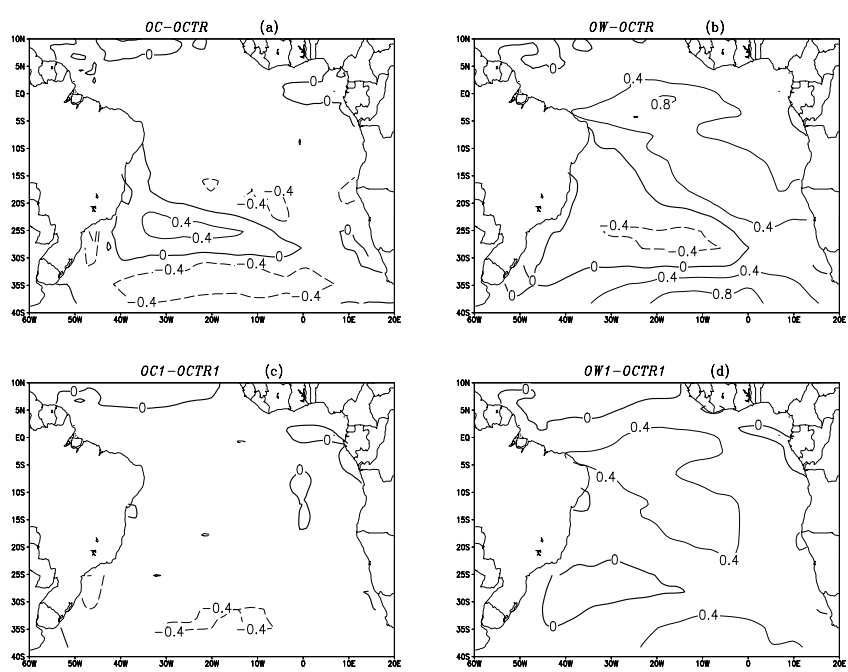

Figure 4. SST difference between (a) $O C$ and $O C T R$, (b) $O W$ and $O C T R$, (c) $O C 1$ and $O C T R 1$, and (d) $O W 1$ and OCTR1 OGCM experiments. Dashed lines represent negative values. Contour interval is $0.4^{\circ} \mathrm{C}$.

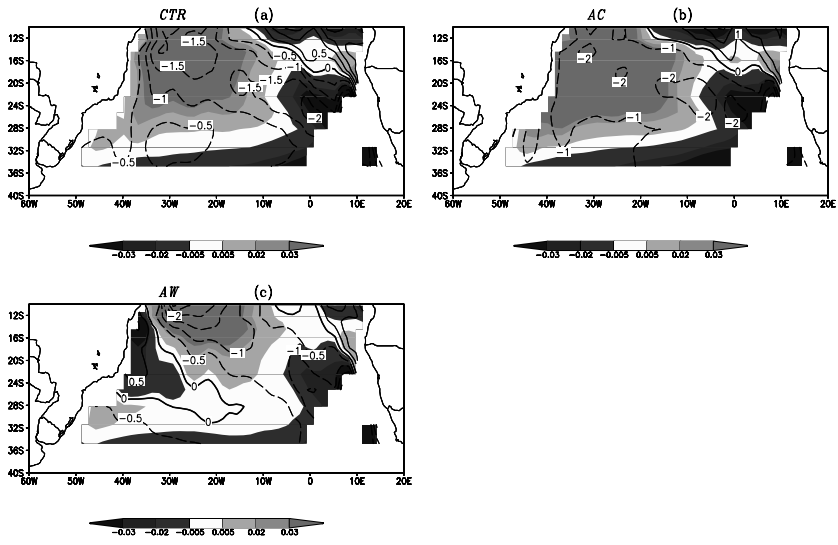

Figure 5. Ekman pumping velocity for (a) $C T R$, (b) $A C$, and (c) $A W$ AGCM experiments (contour). Contour interval is $0.5 \mathrm{~m} /$ month. Vertical temperature advection $\left({ }^{\circ} \mathrm{C} / \mathrm{month}\right)$ (shaded) obtained by Ekman pumping velocity AGCM experiments. Dark shades represent upwelling.

of the SACZ. In the warm experiment (Figure 2c) the OLR pattern was similar to the control run (Figure 2a), but the convection is more intense, with a maximum over southern Northeast Brazil (Nordeste) and intensification of the oceanic portion of the SACZ. In the $C T R$ and $A W$ experiments the maximum of convection was found northward of the region of positive SSTA maximum shown in Figure 1.

[11] The DJF surface heat budget (Short Wave net (SW) + Long Wave net (LW) + Latent Heat Flux (LH) + Sensible Heat (SH) Flux) for the $C T R, A C$, and $A W$ ACGM experiments and the NCEP/NCAR reanalysis climatological mean for DJF 2000/2001 are presented in Figure 3. In this positive values correspond to heat lost by the ocean. For the $A W$ experiment there was surface heat loss on the western South Atlantic (Figure 3c) possibly associated with the reduction of the incident SW in the region of the SACZ due to the increased cloudiness, and increased LH flux (not shown) associated with the larger SST contrast between the ocean and the atmosphere locally. In the $A C$ experiment (Figure 3b), the energy budget showed a pattern that resembles the climatological field derived from the NCEP/NCAR reanalysis (Figure 3d), with warming by SW flux over most of the basin.

\subsection{OGCM Experiments}

[12] Figures $4 \mathrm{a}$ and $4 \mathrm{~b}$ show SST differences for the OGCM experiments (OC minus OCTR and $O W$ minus $O C T R$ ) forced with momentum and SW fluxes from the respective AGCM experiments. The cloudiness associated with the increased SACZ in the $A W$ experiment (Figure 2c) reduced the net radiative energy input into the South Atlantic Ocean, thus decreasing the SST in the western and central South Atlantic (Figure 4b). The more pronounced SST differences occur in the central region of the basin, with a cooling rate of approximately $0.4^{\circ} \mathrm{C}$ per month. On the other hand, possibly, associated with the reduction of cloud cover in the $A C$ experiment (Figure 2b) the SST warmed locally (Figure 4a). These results suggest that a negative feedback process between the SST and the atmosphere occurs over regions adjacent to the SACZ. This result is also consistent with the heat budget in $A W$ and $A C$ experiments that show, 
respectively, surface loss and gain of net energy in the oceanic region under the SACZ (Figures $3 b$ and $3 c$ ). However, when the OGCM was forced with momentum fluxes from the AGCM experiments and climatological SW flux from the Smithsonian Meteorological Tables, the SST differences OC1 minus OCTR 1 and OW1 minus OCTR 1 were smaller (Figures $4 \mathrm{c}$ and $4 \mathrm{~d}$ ). This suggests that the negative dynamic feedback is weaker than the negative thermodynamic feedback in the interactions between the ocean and the atmosphere in the region of the SACZ. In the experiments that used either AGCM or climatological SW no significant SST differences were detected over other ocean areas.

[13] To evaluate the importance of the Ekman pumping feedback due to the curl of surface winds associated with the formation of the SACZ, the Ekman pumping velocity (Figure 5, contours) was calculated from the AGCM experiments wind fields using Equation 3 below, from Curtis and Hastenrath [1995].

$$
W_{e}=\left(\frac{1}{f} \frac{\partial \tau_{y}}{\partial x}-\frac{1}{f} \frac{\partial \tau_{x}}{\partial y}+\frac{\tau_{x} \beta}{f^{2}}\right) \rho_{w}^{-1}
$$

where $\tau_{x}$ and $\tau_{y}$ are the zonal and meridional components of the surface wind stress, $\rho_{w}=10^{3} \mathrm{~kg} \mathrm{~m}^{-3}$ is the water density, $f$ is the Coriolis parameter and $\beta$ is the variation of $f$ with latitude.

[14] The results showed that the effect of surface cooling due to Ekman pumping happens only during strong SACZ events (warm case), as can be seen in Figure 5c. The heating rate of the ocean surface due to Ekman pumping was determined by computing the vertical temperature advection. To determine the variation of temperature with height, the thermocline was considered to coincide with the $20^{\circ} \mathrm{C}$ isotherm, with an average depth of 100 meters at $20^{\circ} \mathrm{S}$. These values were based in OCTR, $O W$ and $O C$ experiments. The Figure 5 (shaded) shows surface cooling only in the $A W$ experiment, with vertical temperature advection of the order of minus $0.02^{\circ} \mathrm{C}$ per month along the southeastern and northeastern coasts of Brazil. The upwelling was more vigorous near the coast and presented a horizontal pattern similar to the SACZ (Figure 5c, shaded), i.e., with a NW/SE structure over the South Atlantic. These results indicate that in the interaction between the SACZ and SST over the South Atlantic, the negative thermodynamic (Cloud/Short-Wave SST) feedback is one order of magnitude larger than the dynamic feedback associated with Ekman pumping.

\section{Conclusions}

[15] The results of the numerical AGCM and OGCM experiments presented in this article support the hypothesis that SACZ variability has a component forced by SST, in agreement with previous works. The existence of warm SST anomalies over the South Atlantic tend to intensify and move the SACZ northward, while cold SST anomalies tend to weaken this system over land and sea in the AGCM $C P T E C / C O L A$. In addition, the results presented here suggest that cold SST anomalies frequently observed beneath the SACZ over the South Atlantic might be the result of radiative processes, with the SACZ forcing the ocean thermodynamically. With the intensification of the SACZ, the SST beneath it cools down primarily due to the cut off incoming shortwave solar radiation associated with to the increased cloud cover. The results also showed that the thermodynamic (Cloud/SW-SST) feedback predominates over the dynamic Ekman pumping feedback by an order of magnitude, and the last is effective to change SST only during strong SACZ events. The SACZ variability is associated with external factors to it region, but the results present here show too that the SST over the South Atlantic has importance. Results presented here were based on CPTEC/COLA AGCM and MOM2 OGCM simulations with prescribed boundary conditions. In order to evaluate the dependence of these results, they must be compared with other model simulations and observational data.

[16] Acknowledgments. The authors thank Vernon Kousky, Prakky Satyamurty, Carlos Nobre, and the anonymous reviewers for their helpful comments on the manuscript. This work represents a portion of Rosane Chaves's Ph.D. Dissertation at INPE and was supported by CNPq. Rosane Chaves have been supported by project under grant $\mathrm{N}^{\mathrm{O}}$ IAI/CRN-055.

\section{References}

Barreiro, M., P. Chang, and R. Saravanan (2002), Variability of the South Atlantic Convergence Zone simulated by an atmospheric general circulation model, J. Climate, 15, 745-763.

Cavalcanti, I. F. A., J. A. Marengo, P. Satyamurty, C. A. Nobre, I. Trosnikov, J. P. Bonatti, A. O. Manzi, T. Tarasova, C. D’Almeida, B. Sampaio, L. P. Pezzi, C. C. Castro, M. Sanches, and H. Camargo (2002), Global climatological features in a simulation using CPTEC/COLA AGCM, J. Climate, 15, 2965-2988.

Curtis, S., and S. Hastenrath (1995), Forcing of anomalous sea surface temperature evolution in the tropical Atlantic during Pacific warm events, J. Geophys. Res., 100(C8), 15,835-15,847.

Doyle, M. E., and V. R. Barros (2002), Midsummer Low-Level Circulation and Precipitation in Subtropical South America and Related Sea Surface Temperature Anomalies in the South Atlantic, J. Climate, 15, 33943410 .

Hastenrath, S., Ed. (1995), Climate and Circulation of the Tropics, in Climate and Circulation of the Tropics, pp. 455, D. Reidel Publishing Company, Madison.

Huang, B., and E. K. Schneider (1995), The response of an ocean general circulation model to surface wind stress produced by an atmospheric general circulation model, Mon. Wea. Rev., 123, 3059-3084.

Kalnay, E., K. C. Mo, and J. Paegle (1986), Large-Amplitude, Short-Scale Stationary Rossby Waves in the Southern Hemisphere: Observations and Mechanistic Experiments to Determine their Origin, J. Atmos. Sci., 43, $252-275$.

Lenters, J. D., and K. H. Cook (1999), Summertime Precipitation Variability over South America: Role of the Large-Scale Circulation, Mon. Wea. Rev., 127, 409-431.

Pacanowski, R. C., K. Dixon, and A. Rosati (1993), The GFDL Modular Ocean Model User's Guide, Version 1.0, GFDL/NOAA, GFDL Ocean Group Tech. Rep. No. 2.

Palastanga, V., C. S. Vera, and A. R. Piola (2002), On the leading modes of sea surface temperature variability in the South Atlantic Ocean, Exchanges, 25.

Robertson, A. W., and C. R. Mechoso (2002), Interannual and Interdecadal Variability of the South Atlantic Convergence Zone, Mon. Wea. Rev., $128,2947-2957$.

Rosati, A., and K. Miyakoda (1988), A general circulation model for upper ocean simulation, J. Phys. Ocean., 18, 1601-1626.

Schneider, E. K., and Z. Zhu (1998), Sensivity of the simulated annual cycle of seas surface temperature in the equatorial Pacific to sunlight penetration, J. Climate, 11, 1932-1950.

Sterl, A., and W. Hazeleger (2003), Coupled variability and air-sea interaction in the South Atlantic Ocean, Clim. Dynamics, in print.

Venegas, S. A., L. A. Mysak, and D. N. Straub (1997), Atmosphere-ocean coupled variability in the south Atlantic, J. Climate, 10, 2904-2920.

R. R. Chaves, IAG/USP, Rua do Matão, 1226, Cidade Universitária, São Paulo, SP, 05508-900, Brazil. (rosane@model.iag.usp.br)

P. Nobre, Centro de Previsão de Tempo e Estudos Climáticos-CPTEC, Instituto Nacional de Pesquisas Espaciais - INPE, Brazil. 